\title{
Optimization of Scheduling in Ethanol Production from Oil Palm Empty Fruit Bunch Process
}

\author{
Nattamon Sirikanchittavon ${ }^{1}$, Worameth Chitcharoen ${ }^{1}$, and Thongchai Rohitatisha Srinophakhun ${ }^{2, *}$ \\ ${ }^{1}$ Department of Chemical Engineering, Faculty of Engineering, Kasetsart University \\ Bangkok, Thailand \\ ${ }^{2}$ Center of Excellence on Petrochemical and Materials Technology, Department of Chemical Engineering, \\ Faculty of Engineering, Kasetsart University, Bangkok, Thailand \\ *Corresponding author's email: fengtcs [AT] hotmail.com
}

\begin{abstract}
In this research, the scheduling Batch process had done for minimizing the processing time and the highest equipment efficiency of the ethanol production process. Aspen Plus program was used to perform the mass and balances in the steady state part, and Aspen Batch Process Developer program was used to schedule batch parts of the process. The production process from oil palm empty fruit bunch has the ethanol capacity of 9,200 $\mathrm{kg}$ per day. The raw materials are oil palm empty fruit bunch 47,000 $\mathrm{kg}$ per day. There are four production schedules: one hydrolysis tank and one fermentation tank, four hydrolysis tanks and a fermentation tank, one hydrolysis tank and four fermentation tanks, four tanks of hydrolysis and four tanks of fermentation. This can reduce time consumption in one production cycle and less cycle time.
\end{abstract}

Keywords— Ethanol Production, Scheduling Batch Process, Empty Fruit Bunch, Aspen Batch Process Developer

\section{INTRODUCTION}

In the chemical industries, there are varieties of the chemical process such as Continuous process and Batch process [1]. Some of them have both Continuous and Batch production systems in one plant. It is necessary to schedule the production of the Batch production system to transfer to the Continuous production system. Production scheduling in the Batch process is used to make the process work in a consistent manner. It can also reduce the cost of production by shortening the production time. Moreover, the use of resources is the most effective [7].

In this article, the production schedule of the production system of the ethanol production at 10 ton per day from the oil palm empty fruit bunch had been scheduled to reduce time spent on production and maximize the efficiency of the use of resources. In the production scheduling of the production system, the Aspen Batch Process Developer program was used to schedule the production.

\section{PROCESS MODELLING}

The primary information about ethanol production from oil palm empty fruit bunch process including the compositions of empty fruit bunch, the ethanol production processes from bio-resources and the appropriate condition for producing ethanol was studied. Then, a Flow Diagram using the Aspen Plus program was created to define all equipment used in the process. After that, the appropriate Property Method in accordance with the substance contained within the system and the conditions of each equipment were determined. After finishing simulating the ethanol process, the information obtained from Aspen Plus was then exported to calculate in Aspen Batch Process Developer program for the hydrolysis and fermentation systems in order to achieve a highly efficient production system. The results from the production process simulation and production scheduling were compared using the graphs, then summarized the results. 


\section{RESULTS AND DISCUSSION}

\subsection{Simulation of the ethanol production process from oil palm empty fruit bunches by Aspen Plus.}

This research studied the ethanol production process with a capacity of 9,200 $\mathrm{kg}$ per day. The raw materials were oil palm empty fruit bunches of 47,000 kilograms per day.

The process of ethanol production from the oil palm empty palm consists of four main steps: 1) Pre-treatment to increases the porosity of the material. 2) Hydrolysis to convert cellulose to glucose as shown in Figure 1 . 3) Sugar fermentation process is the biochemical change of glucose into ethanol as shown in Figure 2. 4) Distillation, this step will increase the purity of ethanol to meet the required statement. The flow-chart of all of the steps are illustrated in Figure 3 and the simulated model of ethanol production from the empty fruit bunch, with the capacity of 9,200 kg per day by using Aspen Plus program is shown in Figure 4.

$\begin{array}{lll}\text { Reaction } & \text { Reactant } & \text { Conversion }\end{array}$

\begin{tabular}{ccc}
\hline Cellulose(CISolid) + Water $\rightarrow$ Glucose & Cellulose & 0.9 \\
2 Cellulose(CISolid) + Water $\rightarrow$ Cellubiose & Cellulose & 0.012 \\
Hemicellulose(CISolid) + Water $\rightarrow$ Xylose & Hemicellulose & 0.9 \\
Cellubiose + Water $\rightarrow$ 2 Glucose & Cellubiose & 1 \\
\hline
\end{tabular}

Figure 1: Hydrolysis Reactions

\begin{tabular}{clc}
\hline Reaction & Reactant & Conversion \\
\hline Glucose $\rightarrow 2$ Ethanol $+2 \mathrm{CO}_{2}$ & Glucose & 0.95 \\
3 Xylose $\rightarrow 5$ Ethanol $+5 \mathrm{CO}_{2}$ & Xylose & 0.85 \\
\hline
\end{tabular}

Figure 2: Fermentation Reactions

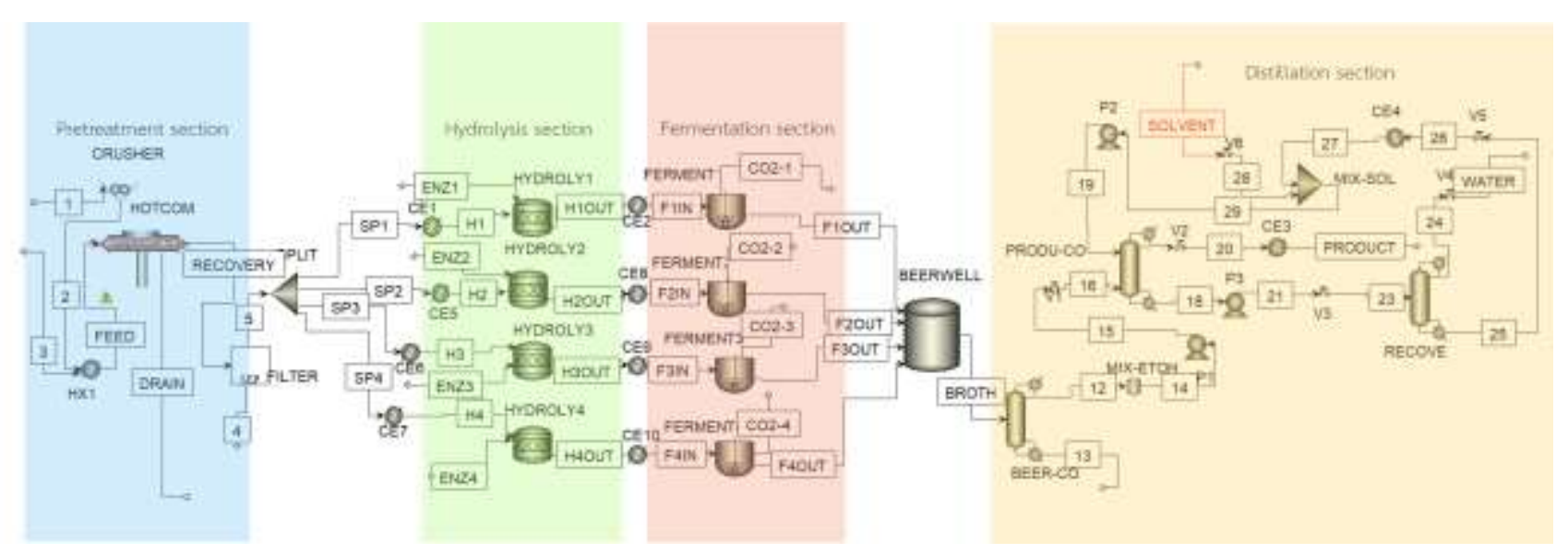

Figure 3: Ethanol production process 


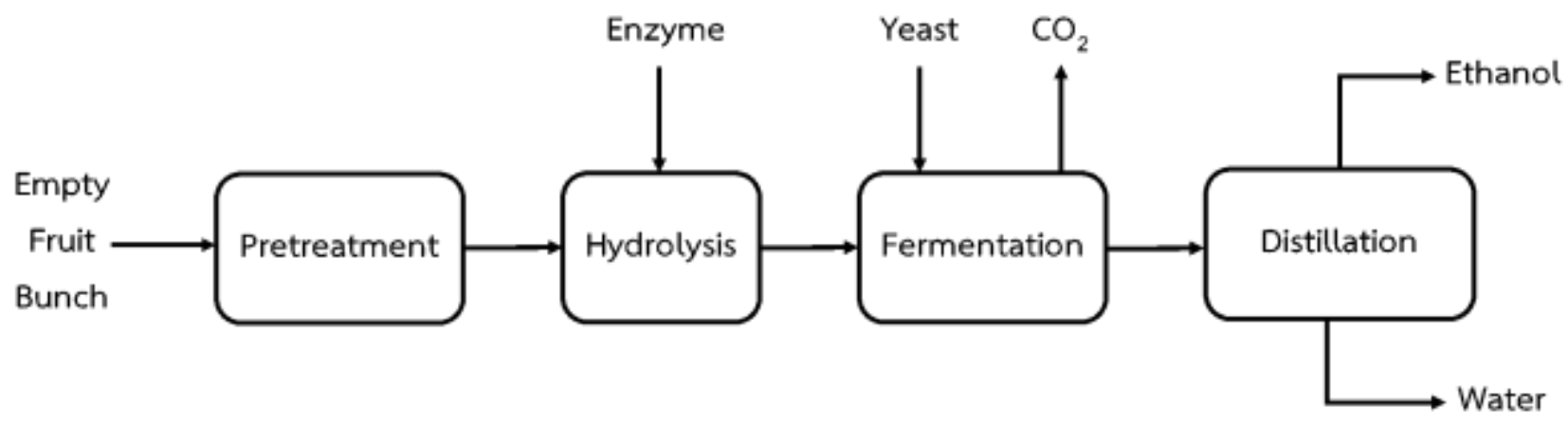

Figure 4: Model of ethanol production process from empty fruit bunch from Aspen Plus

\subsection{Production scheduling in the Hydrolysis and Fermentation by Aspen Batch Process Developer.}

The Aspen Batch Process Developer model was used for a mass balance of substances in the system and was used to display the order of production. Gantt chart was used to display the order of production. The Gantt chart consists of three main parts: the upper part, the left part, and color. The upper part of the table shows the operating time of each equipment in the system and can be used to indicate the cycle time. The left of the table displays the types of equipment used in the system. The color bar shows the operating time of the devices. Four systems were used in this thesis: one tank for hydrolysis and one tank for fermentation, four tanks for hydrolysis and one tank for fermentation, one tank for hydrolysis and four tanks for fermentation, and four tanks for hydrolysis and four tanks for fermentation

\subsubsection{Strategy 1}

The system contains 1 tank of hydrolysis and 1 tank of fermentation. For this system, the inlet flow rate was 276 liters per hour. It took a total of 73 hours to transfer the substance from the storage tank to the hydrolysis tank. The cellulose flow rate was 10,500 kilograms per hour and 3,650 $\mathrm{kg}$ per hour for hemicellulose. It took 1 hour to transfer the substances from hydrolysis tank to fermentation tank. Hydrolysis process took 110 minutes. After that, the substances were transferred from the hydrolysis tank to the fermentation tank. The flow rate of glucose was $3,650 \mathrm{~kg}$ per hour and the flow rate of xylose was $3,735 \mathrm{~kg}$ per hour. It took 1 hour to transfer from hydrolysis tank to the fermentation tank, then fermented for 3 days. Before removing the material from the fermentation tank with an ethanol flow rate of 6,750 kilograms per hour, and took 1 hour to completely remove it. The production scheduling allowed to start the second round of production and it was not necessary to wait for the first round to be finished. The 3-day of fermentation time was defined as the cycle time. The three-dimensional image showing the arrangement of devices and Gannt Chart images are shown in Figures 5 and 6, respectively.

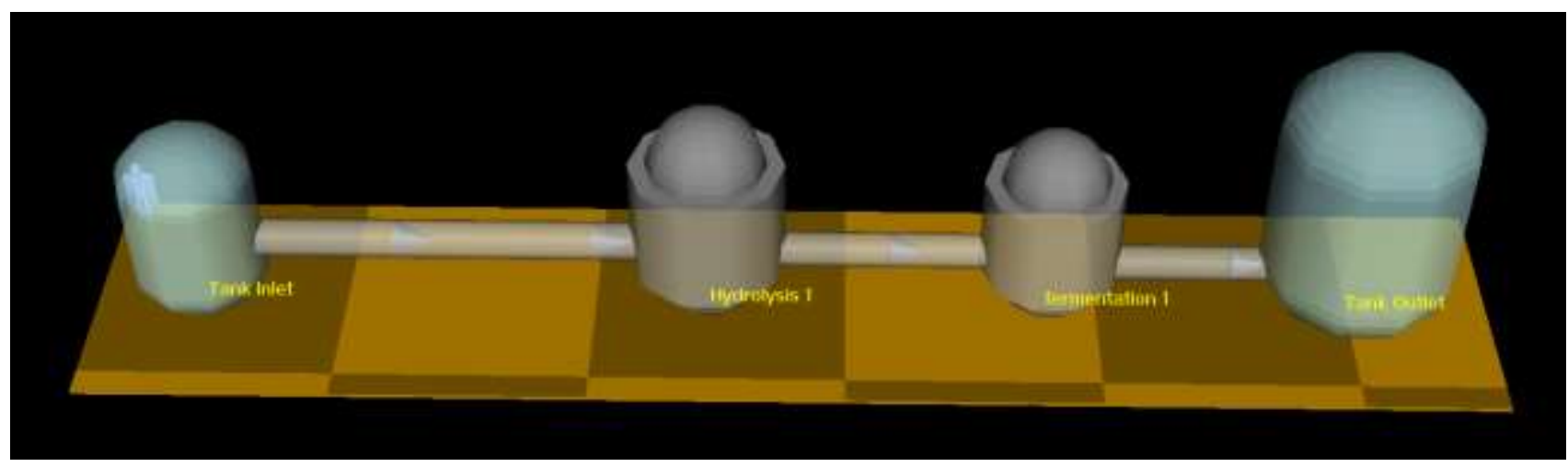

Figure 5: The arrangement of equipment in the ethanol production process for the system with 1 tank of hydrolysis and 1 tank of fermentation.

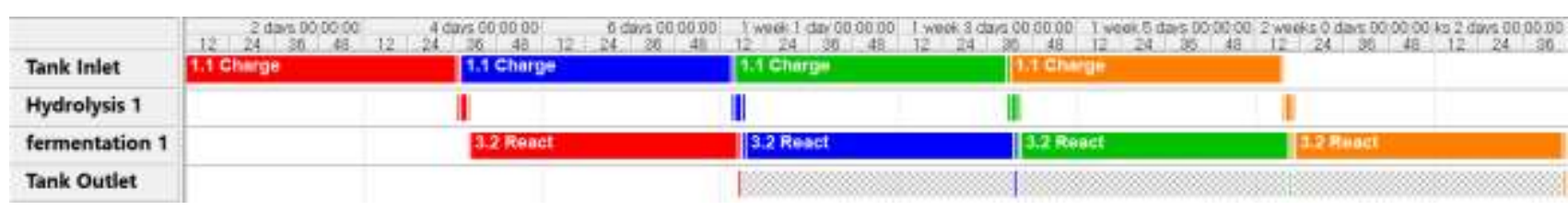

Figure 6: Gantt Chart for the system with 1 tank of hydrolysis and 1 tank of fermentation. 


\subsubsection{Strategy 2}

The system contains 4 tanks of hydrolysis and 1 tank of fermentation. For this system, the inlet flow rate of the substrate was 276 liters per hour. It took 73 hours to complete and then transferred the substances from the inlet tank to the hydrolysis tank. The cellulose flow rate was 10,500 kilograms per hour and hemicellulose flow rate was 3,650 kg per hour. It took 15 minutes to transfer and 110 minutes to hydrolyze cellulose. After completing the hydrolysis step, the substances were transferred from the hydrolysis tank to the fermentation tank. The flow rate of glucose was $3,650 \mathrm{~kg}$ per hour and the flow rate of xylose was 3,735 kilograms per hour with 15 minutes of transferring to each hydrolysis tank. After fermentation for 3 days, the ethanol was transferred from the fermentation tank to the outlet tank with the flow rate of $6,750 \mathrm{~kg}$ per hour for 15 minutes. It took time less than half for this scheduled system compare to the non-scheduled system since production without production schedules needed to wait for the first production to finish. A $3 \mathrm{D}$ image which shows the arrangement of the equipment and Gannt Chart image are presented in Figures 7 and 8, respectively.

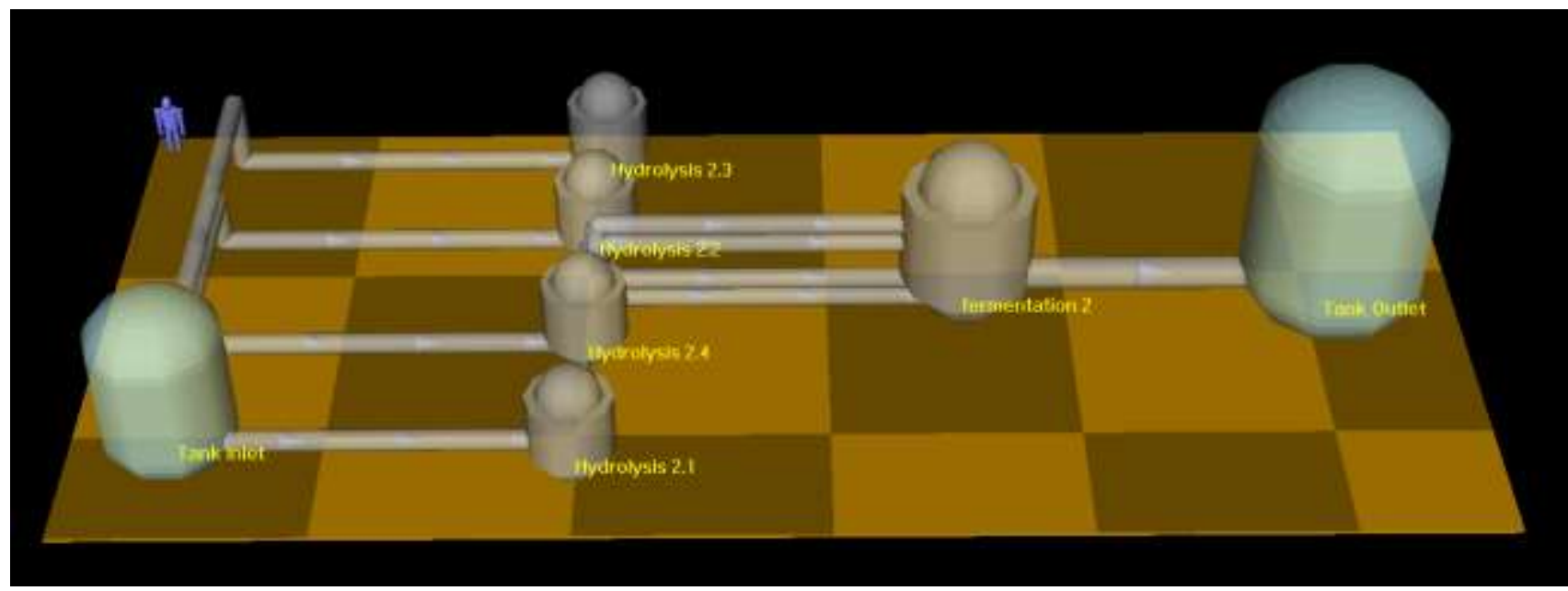

Figure 7: The arrangement of equipment in the ethanol production process for the system with 4 tanks of hydrolysis and 1 tank of fermentation.

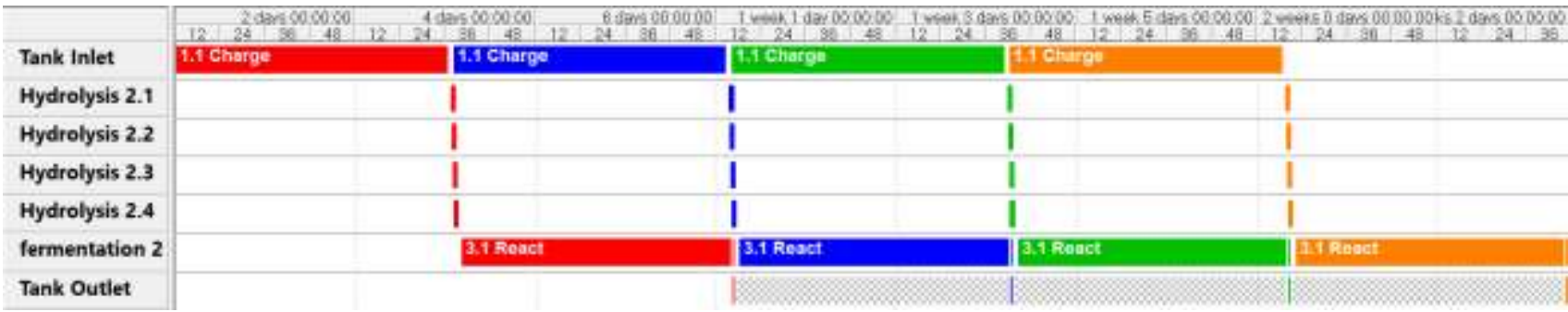

Figure 8: Gantt Chart for the system with 4 tanks of hydrolysis and 1 tank of fermentation.

\subsubsection{Strategy 3}

The system contains 1 tank of hydrolysis and 4 tanks of fermentation. For this system, the inlet flow rate of the substrate was 276 liters per hour with 18 hours of time-consuming. Then transferred the substance from the storage tank to the hydrolysis tank for 15 minutes. The cellulose flow rate was 10,500 kilograms per hour. Hemicellulose was 3,650 $\mathrm{kg}$ per hour. After that, the substances were hydrolyzed for 110 minutes. When hydrolysis was complete, the substances were moved from the hydrolysis tank to the fermentation tank. The flow rate of glucose was 3,650 kilograms per hour. The flow rate of sugarcane was $3,735 \mathrm{~kg}$ per hour. It took 15 minutes to move to the fermentation tank and then fermented for 3 days. The fermentation was carried out with the ethanol flow rate of 6,750 kilograms per hour and took 15 minutes for this step. A 3D image which shows the arrangement of the equipment and Gannt Chart image was presented in Figures 9 and 10, respectively. 


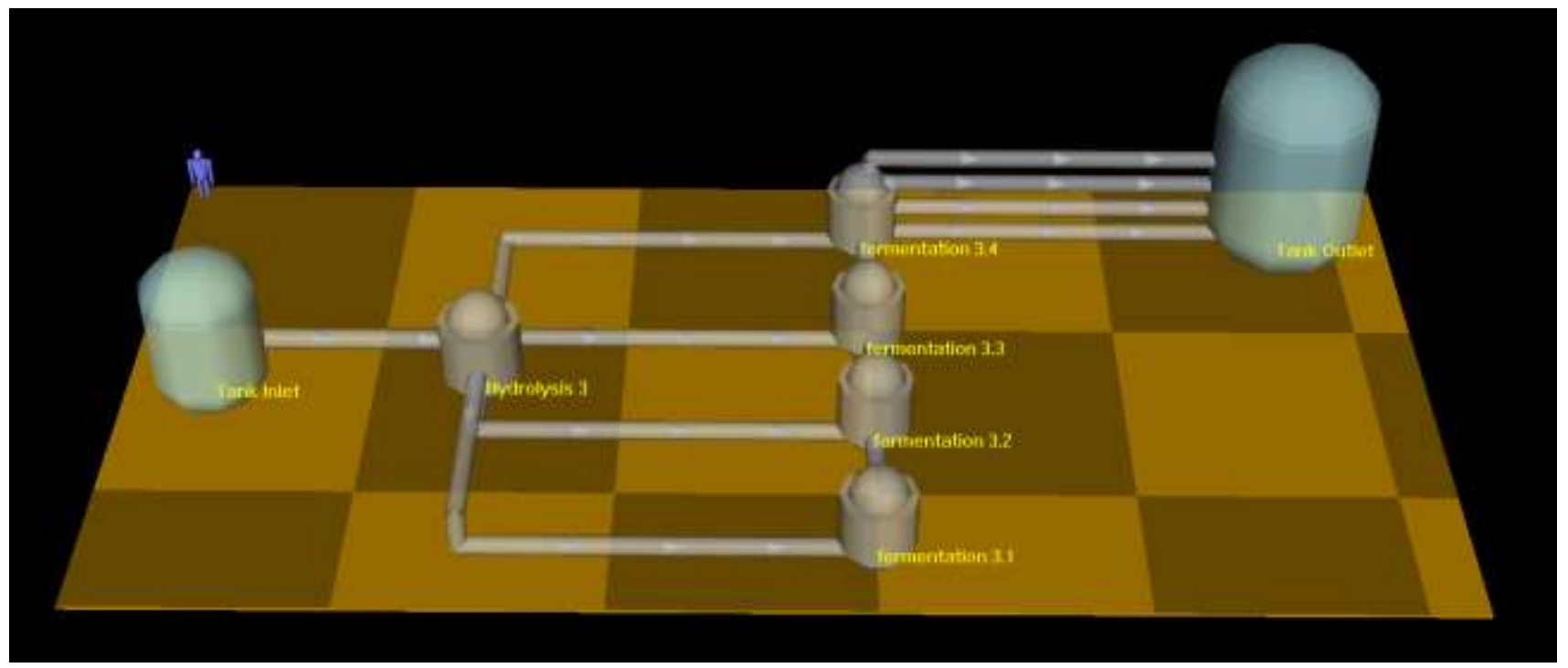

Figure 9: The arrangement of equipment in the ethanol production process for the system with 1 tank of hydrolysis and 4 tanks of fermentation.

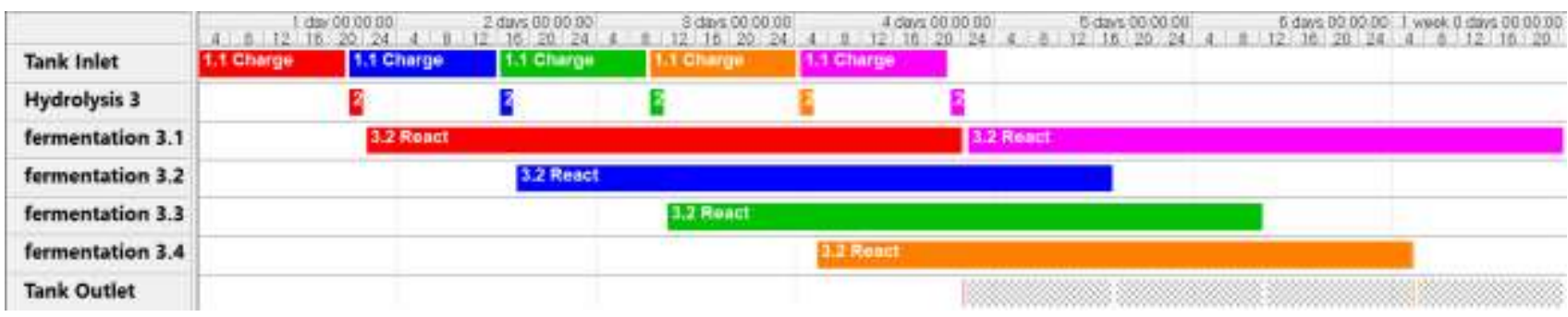

Figure 10: Gantt Chart for the system with 1 tank of hydrolysis and 4 tanks of fermentation.

\subsubsection{Strategy 4}

The system contains 4 tank tanks and 4 tank tanks. For this system, the inlet flow rate of the substrate was 276 liters per hour. It took 18 hours to transfer and then transferred the substances from the inlet tank to the hydrolysis tank. The cellulose flow rate was $10,500 \mathrm{~kg}$ per hour and hemicellulose was 3,650 kg per hour. It took 15 minutes to complete the hydrolysis and then hydrolyzed for 110 minutes. After that, the substances were moved from the hydrolysis tank to the fermentation tank. The flow rate of glucose was 3,650 kilograms per hour. The flow rate of sugarcane was 3,735 kg per hour, lasted for 15 minutes. After 3-days of fermentation, the process carried out with the ethanol flow rate of $6,750 \mathrm{~kg}$ per hour with 15 minutes of transferring. A three-dimensional image showing the arrangement of devices and Gannt Chart images were shown in Figures 11 and 12, respectively. 


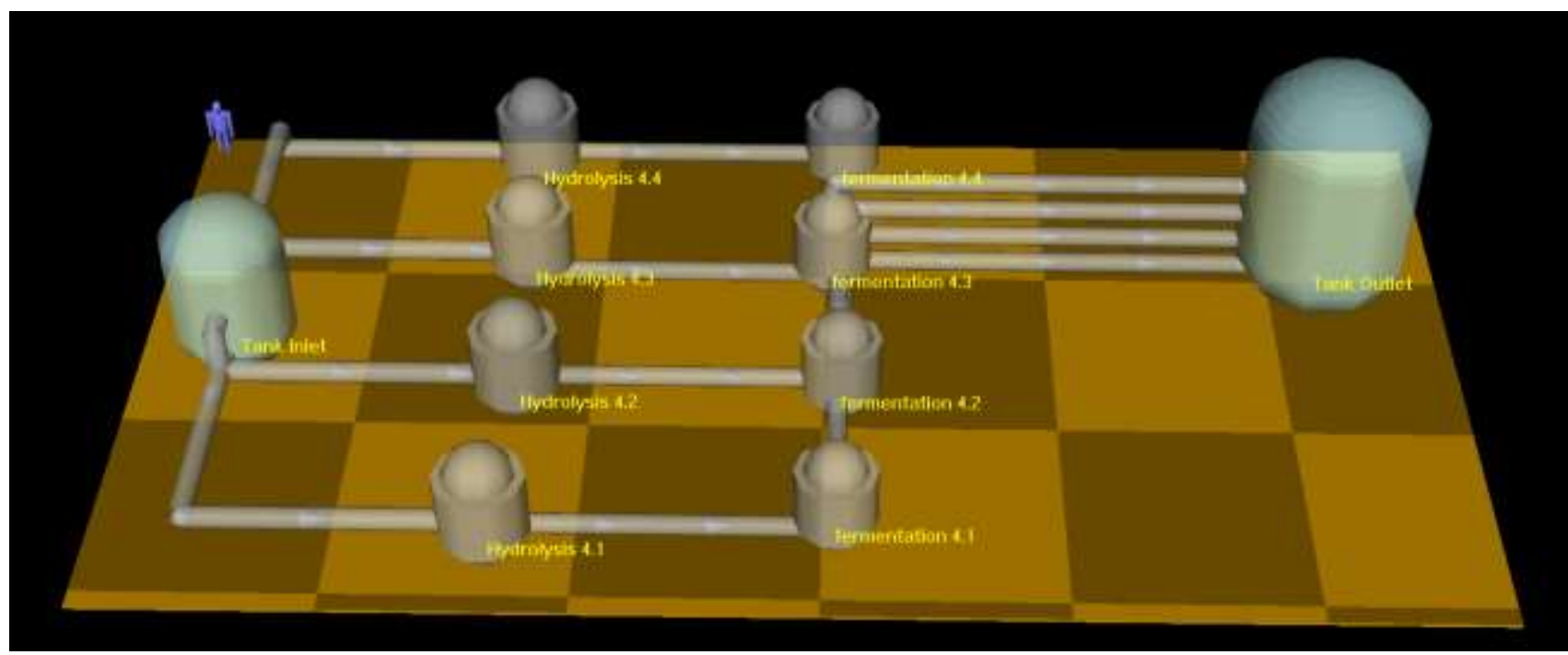

Figure 11: The arrangement of equipment in the ethanol production process for the system with 4 tanks of hydrolysis and 4 tanks of fermentation

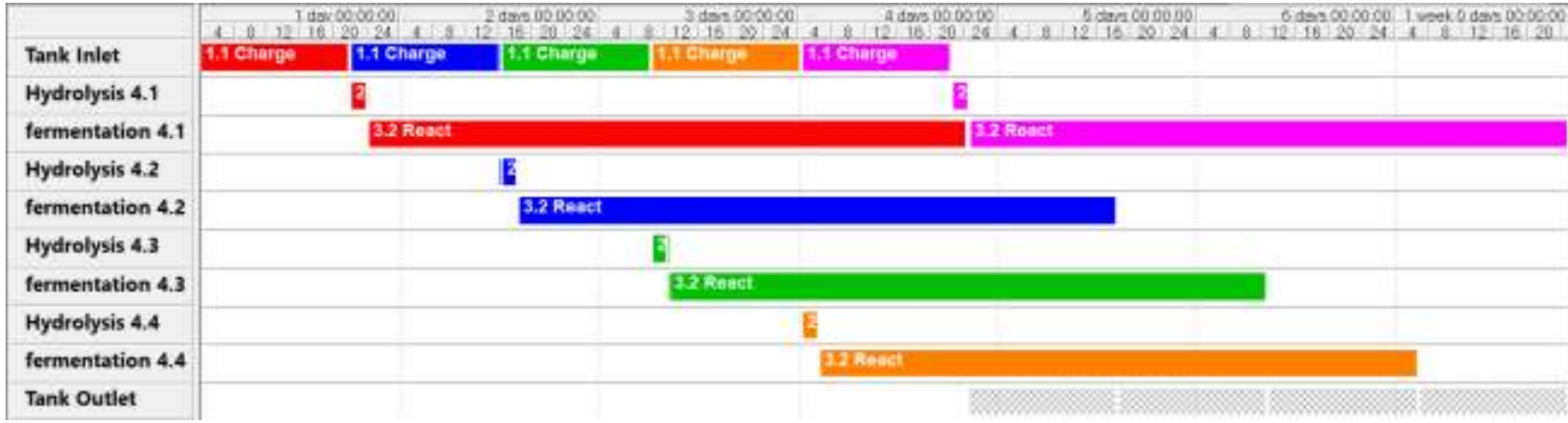

Figure 12: Gantt Chart for the system with 4 tanks of hydrolysis and 4 tanks of fermentation.

\subsection{Comparison of time spent on each production cycle.}

The production scheduling of the four different systems: one hydrolysis tank and one fermentation tank, four hydrolysis tanks and one fermentation tank, one hydrolysis tank and four fermentation tanks, four hydrolysis tanks and four fermentation tanks. It gave the results of the time spent in each production cycle and the different of cycles time as shown in Figures 13 and 14. Figure 13 shows that the effect of the number of hydrolysis tanks was very small. Meanwhile, more fermentation tanks result as a decreasing in time spending on the process significantly. Figure 14 illustrates that the number of hydrolysis tanks did not affect the cycle time. The greater the number of fermentation tanks, the lower of the Cycle Time. 


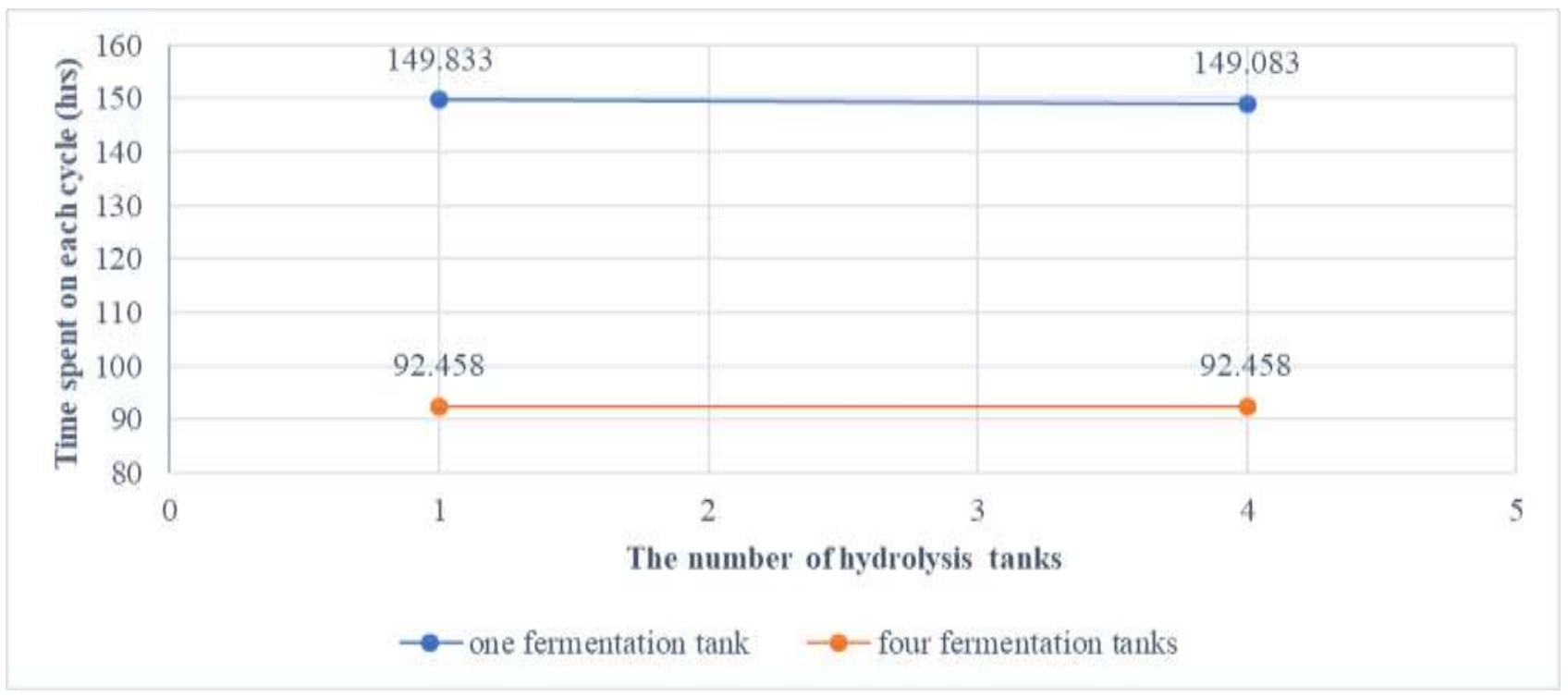

Figure 13: The relationship between the number of tanks in the system and the time spent on producing ethanol in one production cycle.

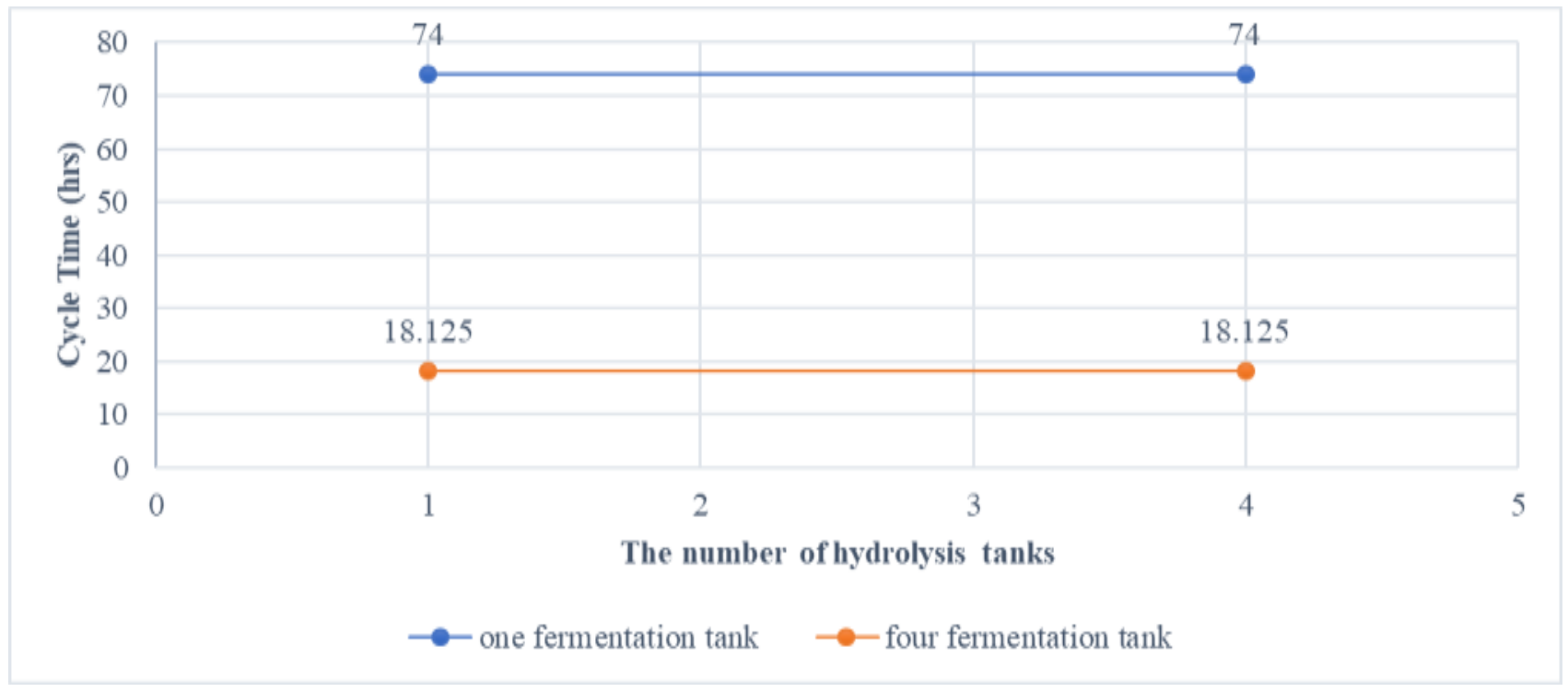

Figure 14: Relationship between the number of tanks in the system and Cycle Time.

\section{CONCLUSION}

Calculation of steady-state balanced the ethanol production from empty oil palm empty fruit bunch. It was found that ethanol was produced $9,200 \mathrm{~kg}$ per day. The raw materials were oil palm empty fruit bunch of 47,000 kilograms per day. It was found from the production schedule that the system could be operated in system co-operated between batch and continuous processes. For the case of one hydrolysis tank and one fermenter tank, the system worked for 1 cycle at 149.83 hours and the cycle time was 74 hours. For the case of four hydrolysis tanks and one fermentation tank, the system took about 149.08 hours for 1 cycle and had a cycle time of 74 hours. In the case of one hydrolysis tanks and four fermentation tanks, there was a time spend of 92.46 hours and a cycle time of 18.125 hours. In the case of four hydrolysis tanks and four fermentation tanks, the system ran for one cycle at 92.46 hours. Cycle Time was 18.125 hours. It can be concluded that when the number of fermenters increases, the time spend on one cycle and the cycle time is reduced due to the length of time used in the fermenter for the longest time compared to other equipment in the system. 


\section{ACKNOWLEDGEMENTS}

This research was supported by to the Faculty of Engineering, Department of Chemical Engineering, Kasetsart University.

\section{REFERENCES}

[1] Warren D. Seider, J.D. seader, Daniel R. Lewin, Product and Process Design Principles Synthesis, Analysis, and Evaluation. 2nd ed., John Wiley and Sons, New York, 2003

[2] Mofoluwake M. Ishola, Isroi, Mohammad J. Taherzadeh, "Effect of fungal and phosphoric acid pretreatment on ethanol production from oil palm empty fruit bunches (OPEFB)", Bioresource Technology, vol. 165, pp.9-12, 2014

[3] Jegannathan Kenthorai Raman, Edgard Gnansounou, "Ethanol and lignin production from Brazilian empty fruit bunch biomass", Bioresource Technology, vol. 172, pp.241-248, 2014

[4] Jesus David Coral Medina et al, "Steam explosion pretreatment of oil palm empty fruit bunches (EFB) using autocatalytic hydrolysis: A biorefinery approach", Bioresource Technology, vol. 199, pp.173-180, 2014

[5] Diego Piarpuza'n, Julia'n A. Quintero, Carlos A. Cardona, "Empty fruit bunches from oil palm as a potential raw material for fuel ethanol production", biomass and bioenergy, vol. 35, pp.1130-1137, 2011

[6] Nurfahmi et al, "Effects of organosolv pretreatment and acid hydrolysis on palm empty fruit bunch (PEFB) as bioethanol feedstock", Biomass and Bioenergy, vol. 95, pp.78-83, 2016

[7] Qian Yu, Pan Ming, Huang Yacai, "Modeling and Optimization for Scheduling of Chemical Batch Processes", Chinese Journal of Chemical Engineering. vol. 17, pp.1-7, 2009 